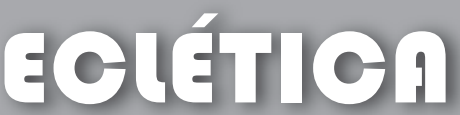 química
}

\section{NEW REAGENTS FOR THE SPECTROPHOTOMETRIC DETERMINATION OF RANITIDINE HYDROCHLORIDE}

\author{
B. Narayana*, K.Veena, K. Ashwani and Divya. N. Shetty \\ Department of P.G. Studies and Research in Chemistry, Mangalore University, Mangalagangotri-574 199, India \\ E.mail: nbadiadka@yahoo.co.uk; Fax: 0091-824-2287367
}

\begin{abstract}
A new spectrophotometric method is proposed for the assay of ranitidine hydrochloride (RNH) in bulk drug and in its dosage forms using ceric ammonium sulphate (CAS) and two dyes, malachite (MAG) green and crystal violet (CV) as reagents. The method involves the addition of a known excess of ceric ammonium sulphate to ranitidine hydrochloride in acid medium, followed by the determination of unreacted CAS by reacting with a fixed amount of malachite green or crystal violet and measuring the absorbance at 615 or $582 \mathrm{~nm}$ respectively against the reagent blank. The Beer's law is obeyed in the concentration range of 0.4-8.0 $\mu \mathrm{g} /$ $\mathrm{ml}$ of ranitidine hydrochloride $(\mathrm{RNH})$ for $\mathrm{RNH}-\mathrm{MAG}$ system and $0.2-1.6 \mu \mathrm{g} / \mathrm{ml}$ of ranitidine hydrochloride for RNH-CV system. The molar Absorptivity, Sandell's sensitivity for each system were calculated. The method has been successfully applied to the determination of ranitidine hydrochloride in pure and dosage forms.
\end{abstract}

Key words: Spectrophotometry; Ranitidine hydrochloride; Ceric ammonium sulphate; Malachite green; Crystal violet

\section{Introduction}

Ranitidine hydrochloride ( $\mathrm{RNH})$, chemically, is N, N-dimethyl-5-[2-(1-methylamino-2-nitrovinyl) - ethylthiomethyl] furfurylamine hydrochloride. The drug was introduced in the market in 1981. The drug is official in Indian Pharmacopoeia [1]. It is a H2- receptor antagonist and is widely used in short term treatment of duodenal and gastric ulceration, reflux oesophagitis and dyspepsia $[2,3]$. When used at the usual recommened dose, ranitidine has been found to be safe [4]. Earlier studies have indicated that ranitidine was oxidized by the liver micosomal oxidases and was converted to its $\mathrm{N}$-oxidase, S-oxide and desmethyl metabolites [5,6,7]. Among these hepatic microsomal ranitidine metabolites, ranitidine $\mathrm{N}$-oxide produced by the hepatic microsomal-flavin-containing monooxygenase (FMO) has been found to be the major metabolite excreted in human urine. Thus measuring the amount of ranitidine $\mathrm{N}$-oxide present in urine after administration of ranitidine has been used as a non-invasive method of determining the human liver FMO activity in vivo [8]. Several techniques such as proton magnetic resonance spectroscopy [9], near infrared reflectance spectrometry [10], scintillation proximity assay [11], flow injection fluorimetry [12], polarography $[13,14]$, differential pulse polarography [15], capillary electrophoresis [16], high performance liquid chromatography $[17,18]$ have been used for the determination of RNH in pharmaceuticals. These techniques require sophisticated instruments and expensive reagents, and involve several manipulation steps and derivatization reactions. These methods, however, are not adaptable for use in pharmokinetic studies because of their lack of selectivity. Among these instrumental analyti- 
cal techniques, spectrophotometric techniques occupies a unique position, because of its simplicity, sensitivity, accuaracy and rapidity.

Literature survey revealed that the only tiLic med [19] reported for RNH requires $300 \mathrm{mg}$ of drug for each titration. There re few methods for the spectrophotometric determination of ranitidine. These are based on the reaction of ranitidine with some organic acidic dyes followed by extraction of the colored ion-pairs into organic solvents and absorbance measurements. Spectrophotometric determination of ranitidine in tablets has been also suggested through chromogenic reactions with 3-methylbenzothiozline-2-one hydrazone [20], 3,5-dichloro-pbenzoquinone chlorimine [20], Folin-Ciocalteu [21] roguno Therinine [20], Foli-Ciocalteu [21] reagents. These medse for time for color development (15- $30 \mathrm{~min})$, they time for color development $(15-30 \mathrm{~min})$, they require prior extraction of the colored reaction product
$\left(-90^{\circ} \mathrm{C}\right)$.

In this communication, we demonstrate the use of spectrophotometric techniques for the determination of RNH. The present work involves sensitive, selective and cost effective metheds for the determination of ranitidine hydiochloride. The method utilizes ceric ammonium sulphate and two dyes malachite green and crystal violet. Spectrophotometric techniques are in good agreement with the reported methods. In addition, it is not susceptible to interference from common tablet excipients. The developed method has been successfully applied to the determination of ranitidne hydrochloride in pure and dosage form.

\section{Experimenta}

\section{Aparatus}

A SHIMADZU UV-2550 UV-VIS Spectrophotometer with $1 \mathrm{~cm}$ matched quartz cells were used for the absorbance measurements.

\section{Reagents and Solutions}

All reagents used were of analytical reagen grade and distilled water was used for the preparation of all solutions. A $1000 \mu \mathrm{g} / \mathrm{ml}$ standard drug solution of ranitidine hydrochloride was prepared in distilled water. The stock solution was diluted appropriately to get the working concentration.

Ceric ammonium sulphate $(0.01 \mathrm{M})$ was prepared in $1 \mathrm{M}$ sulphuric acid and standardized. This was diluted stepwise to obtain the working concentrations containing $400 \mu \mathrm{g} / \mathrm{ml}$ (RNH-MAG system) and $900 \mu \mathrm{g} / \mathrm{ml}$ (RNH-CV system). . crystal violet $(0.05 \%)$ were also used.

\section{Procedure}

Method A

Different aliquots $(0.4-8.0 \mu \mathrm{g} / \mathrm{ml})$ of RNH were transferred in to a series of $10 \mathrm{ml}$ calibrated flasks by means of a micro burette. Then, $1 \mathrm{~m}$ of $5 \mathrm{M} \mathrm{HCl}$ was added followed by $1 \mathrm{ml}$ of CAS solution. The contents were shaken well and were set aside for 15 minutes with occasional shaking. Then, $1.0 \mathrm{ml}$ of malachite green was added to each flask, and the volume was adjusted up to the mark with distilled water and mixed well. The absorbance of each solution was measured at $615 \mathrm{~nm}$ ainst the correponding reagent blank. The abgainst he coresponing reant blat, The absorbance corresponds to the bleached color, which in turn coresponds to the drug solution, was obtained by subtracting the absorbance of the blank by that of the test solution.

\section{Method B}

Different aliquots (0.2-1.6 $\mu \mathrm{g} / \mathrm{ml})$ of RNH were transferred in to a series of $10 \mathrm{ml}$ calibrated flasks by means of a micro burette. Then, $1 \mathrm{ml}$ of $5 \mathrm{M} \mathrm{HCl}$ was added followed by $1 \mathrm{ml}$ of CAS solution. The contents were shaken well and were

set aside for 15 minutes with occasional shaking. Then, $0.5 \mathrm{ml}$ of crystal violet was added to eac flask, and the volume was adjusted up to the mark with distilled water and mixed well. The absorbance of each solution was measured at $582 \mathrm{~nm}$ against the corresponding reagent blank. The absorbance corresponds to the bleached color, which in turn corresponds to the drug solution, was obtained by subtracting the absorbance of the blank from that of the test solution.

le 2. Results of assay of formulations by the proposed method using MAG as reagent

\begin{tabular}{ccccc}
\hline Sample & RNH certified & Found \pm SD & Recovery $(\%)$ & ${ }^{\text {at-test }}$ \\
\hline Zinetac & 168.0 & $168.154 \pm 0.495$ & 100.090 & 0.703 \\
Rantac & 168.0 & $167.996 \pm 0.118$ & 99.900 & 0.075 \\
Zenloc & 168.0 & $168.120 \pm 0.463$ & 100.070 & 0.579 \\
\hline
\end{tabular}

Mean \pm Standard deviation $(\mathrm{n}=5)$ [mg/tablet], ${ }^{\circ}$ Tabulated t-value at $95 \%$ confidence level is 2.78 Rantac- J.B.Chemicals Pharmaceuticals Limited, Gujarat Zinetac- GlaxoSmithKline Pharmaceuticals Limited, Nashik Zenloc- Relief Biotech (P) Ltd, Haridwar

Table 3. Results of assay of formulations by the proposed method using CV as reagent

\begin{tabular}{ccccc}
\hline Sample & RNH certified & Found \pm SD $^{\mathrm{a}}$ & Recovery (\%) & ${ }^{\mathrm{a}}$-test \\
\hline Zinetac & 168.0 & $168.224 \pm 0.340$ & 100.130 & 1.470 \\
Rantac & 168.0 & $167.976 \pm 0.08$ & 99.980 & 0.671 \\
Zenloc & 168.0 & $168.096 \pm 0.110$ & 100.057 & 1.812 \\
\hline
\end{tabular}

Mean \pm Standard deviation ( $\mathrm{n}=5$ ) [mg/tablet], ${ }^{\mathrm{b}}$ Tabulated t-value at $95 \%$ confidence level is 2.78 Rantac- J.B.Chemicals Pharmaceuticals Limited, Gujarat

Zinetac- GlaxoSmithKline Pharmaceuticals Limited, Nashik

Zenloc- Relief Biotech (P) Ltd, Haridwar

\section{Result and discussion}

In this work, a method based on spectrophotometry was developed and validated for ranitidine hydrochloride in pure and dosage form. In recent years, the development of spectrophotometric methods for determinations of drugs has increased considerable, due to their importance, low cost, and simplicity. Before applying an analytica method in the quality control, it is necessary to validate it. The validation testifies that the procedure is suitable for the intended purpose. The International Conference on the Harmonization of Technical Requirements for the Registration of Pharmaceuticals for Human Use (ICH 2005) and USP 30 (USP 30, 2007) guidelines describe the analytical parameters that should be evaluated in 
a method validation. The type of method and its crystal violet measuring the absorbance at $582 \mathrm{~nm}$, respective use determine which parameters should be evaluated. It is the responsibility of the analyst to select the parameters considered relevant for each method [28]. The experimental conditions were chosen after testing the different parameters that influence the analysis. The methods involve the addition of a known excess CAS to ranitidine hydrochloride in acid medium, followed by determination of residual CAS by reacting with a fixed amount of either malachite green measuring the absorbance at $615 \mathrm{~nm}$ (RNH-MAG system), or

RNH-CV system). In the present method all parameters influencing the color development were investigated and are incorporated in the recommeed procedure. When added in increasing concenritions a fixed cons tretions to a fixed coner consumes the latter propotionally and there is conconitant drop in the remaining concentration of CAS. When a fixed dye concentration is added to decreasing concentrations of CAS, a concomitant increase in the dye concentration results. The reaction mechanism are shown in scheme 1.

Scheme.1
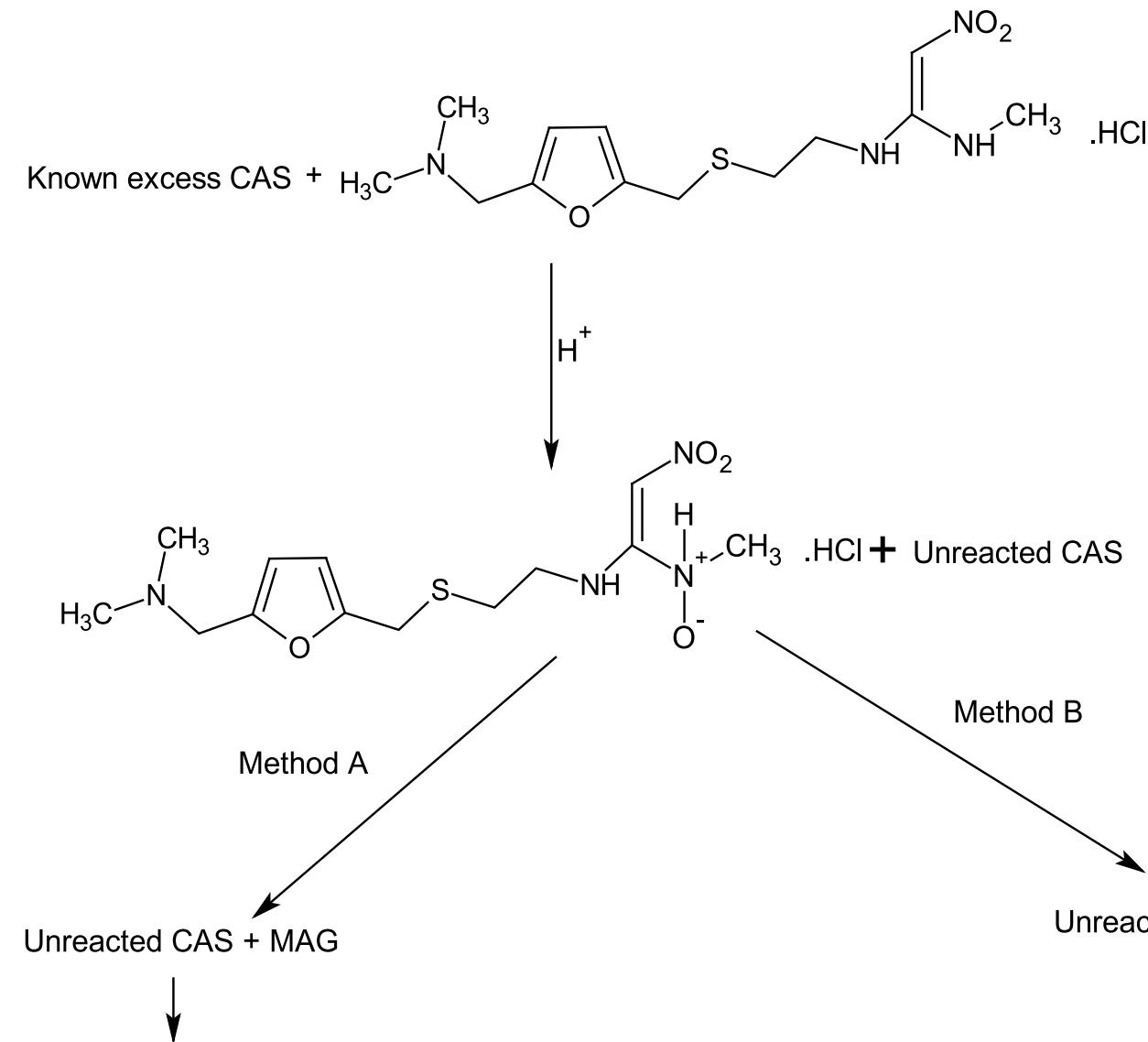

Bleached MAG,measured at $615 \mathrm{~nm}$

Bleached $\mathrm{CV}$, measured at $582 \mathrm{~nm}$

\section{Analytical data}

To assess the linearity, a standard curve for ranitidine hydrochloride was constructed by plotting concentrations versus absorbance and showed good linearity in the range $0.4-8.0 \mu \mathrm{g} / \mathrm{ml}$ of anitidine hydrochloride for RNH-MAG system and $0.2-1.6 \mu \mathrm{g} / \mathrm{ml}$ of ranitidine hydrochloride for RNH-CV system. The correlation coefficients for each system were 0.9945 and 0.9903 indicating good linearity. The accuracy expresses the agreement between the accepted value and the value found. The precision and accuracy of the method Table 4. Evaluation of accuracy and precision Ranitidine hydrochloride (Using MAG as Reagent)

\begin{tabular}{ccccc}
\hline Amount taken $\left(\mu \mathrm{g} \mathrm{mL}^{-1}\right)$ & Amount found $\left(\mu \mathrm{gL}^{-1}\right)$ & Recovery $(\%)$ & SD & RSD (\%) \\
\hline 1.00 & 0.99 & 99.00 & 0.02 & 2.02 \\
2.00 & 1.96 & 98.00 & 0.04 & 2.04 \\
3.00 & 2.97 & 99.00 & 0.02 & 0.67 \\
4.00 & 3.94 & 101.60 & 0.05 & 1.27 \\
5.00 & 5.08 & 98.50 & 0.03 & 0.59 \\
6.00 & 6.02 & 100.30 & 0.02 & 0.33 \\
\hline
\end{tabular}

a- average of five determinations, SD- standard deviation, RE-relative erro

Table 5. Evaluation of accuracy and precision

Ranitidine hydrochloride (Using CV as Reagent)

$\begin{array}{ccccc}\text { Amount taken }\left(\mu \mathrm{g} \mathrm{mL}^{-1}\right) & \text { Amount found }\left(\mu \mathrm{g} \mathrm{mL}^{-1}\right) & \text { Recovery (\%) } & \text { SD } & \text { RSD (\%) } \\ 0.200 & 0.203 & 101.500 & 0.002 & 0.985 \\ 0.400 & 0.405 & 101.250 & 0.002 & 0.490 \\ 0.600 & 0.607 & 101.160 & 0.002 & 0.329 \\ 0.800 & 0.810 & 101.250 & 0.007 & 0.864\end{array}$

$\begin{array}{lllll}0.000 & 0.982 & 98.200 & 0.008 & 0.814\end{array}$

a- average of five determinations, SD-standard deviation, RE-relative error

was studied by analyzing the coupling solution whown amounts of the cited reagent Sandell's sensitivity, slope, intercept for RNH-MAG system is found to be $1.10 \times 10^{4} \mathrm{~L} \mathrm{~mol}^{-1} \mathrm{~cm}^{-}$ RNH-CV system is fore 0.0089 while that for $\mathrm{m}^{-1} \quad 0.007 \mathrm{\mu gm}^{-2}, 0.0424,0.0372$ respective Results of evalution of accuracy and precision for each system are shown in table 4 and 5 . The spe-

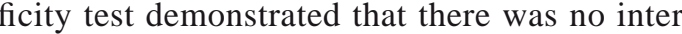
ference in the determination of the drug. 
A new method is described for the spec- which lies between 98.0 and 101.60 reveals that rophotometric determination of ranitidine hydro- the procedures are free from interference from chloride. The proposed method is applied to the usual tablet excipients like talc, starch, calcium determination of ranitidine hydrochloride in pure gluconate, sucrose, etc. and dosage forms. The comparisons of the repor-

Table 1. Comparison of proposed method with earlier methods

\begin{tabular}{ll}
\hline Reagent & Remarks \\
\hline F-C reagent [21] & Less sensitive \\
Bromothymol blue [22] & Involve extraction \\
Rose Bengal [23] & Involve extraction \\
$\mathrm{Hg}(\mathrm{SCN})_{2}$-IRON(III) [24] & Less sensitive \\
$\mathrm{KIO}-\mathrm{DCF}[25]$ & Requires strict pH \\
& control and less \\
& sensitive. \\
$\mathrm{KMnO}_{4} / \mathrm{NBS}$ azine dyes [26] & Involves extraction. \\
Proposed methods & Sensitive \\
& Selective, no interference \\
& from usual tablet \\
& excipients. \\
\end{tabular}

\section{Conclusions}

The method is sensitive, enabling the accurate and precise determination of the analytes over satisfactory concentration ranges without the need of special or laborious sample-pretreatment steps. The method, which is advantageously timeand cost-efficient, was successfully applied to the quantification of the analytes in commercial samples, with results being in good statistical agree ples, wh the repored meth; considered useful for routine quality monitoring considered useful
of pharmaceuticals.

\section{Acknowledgement}

One of the author KV thank UGC for JR
[1] The Indian Pharmacopeia, The Controller of Publications, Ministry of Health and family Welfare, Govt. of India, New Delhi, 1996, pp.659.

[2] R.N.Brogden, A.A. Carmine, R.C. Heel, T.M. Speight,

W. Catterall, K. Mackie, Local anaesthetics. In J. G. Hardman \& L.E. Limdind (Eds.), The pharmalogical basis of .

] G. Tougas, D. Armstrong, Can. J.Gastroenterol 11 (1997) $51 \mathrm{~B}$ (1981)161

6] L.E. Martin, J. Oxford, R.J.N. Yanner, Xenobiotica 11 (1981) 831

7] L.H. Overby, G.C. Carver, R.M. Philpot, Chem. Biol. Interact 106 (1997) 29

I.C.K.Kang, W.G. Chung, K.H.Lee, C.S. Park, J.S.Kang I.C.Shin, H.K.Roh HK, M.S.Dong, H.M.Baek, Y.N.Cha (2000) 67

Ozden, A. Ungovmus, A. Tosun, S. Erasan, Spectroscop. Lett 30 (1997) 835 .S. Avery, Drugs 24 (1982) 267

[5] P. F. Carey, L.E. Matin, P.E. Owen, J. Chromatogr 225
[10] E. Dreassi, G. Ceramelli, P.Corti, P.L. Perruccio, S. Lonardi, Analyst 121 (1996) 219

11] S. Fenwick, W.N. Jemner, P. Linacre, R.M. Rooney, S.A. Ring, Anal. Proc. 31(1994) 103.

12] [12] C. Lopez-Erroz, H.Vhas, N.Campillo, M.Hernandez-

Cardoba, Analyst 121 (1996) 1043

[13] P. Richter, M.I. Toral, F. Munoz-Varzas Analyst 119 (1994) 1371

14] A.Z.Abu-Zuhri, M. Hannoun, S.I.Al-Khalil, H. Hasan, Anal. Lett. 21 (1988) 1845.

[15] P.S.Sankar, S.J.Reddy, Indian.J. Pharm. Sci 51 (1989) 263

[16] M.A. Kelly, K.D.Altria, C.Grace, B.J.Clark, J.Chromatogr 798 (1996) 297

[17] G. Bettermann, S. Cabrera, S. Heizenroeder, D. Lubda, Labor Praxis 22 (1998) 30

[18] G.L. Iloyer, J. Le Doux, P.E. Nolan Jr, J. Liq. Chromatog 18 (1995) 1239.

19] Z. Atkosar, M. Tunsel, Acta. Pharm. Turc 31 (1989)139 [20] E.V.Rao, P.J.Rao, S.S.N. Murty, G.R.Rao Indian .J Pharm Sci.49 (1987) 143

21] G.R. Rao, A.B.Avadhanulu, D.K.Vatsa DK, Indian Drugs (2) Y. Ozsoy, B.G

27. Ozsoy, B.Guvner, Acta. Pharm. Turc 29 (1987) 13

24] K. Basavaiah, B.C. Somashekar Ecl Quím 32 (2007) 19 .J .Chem. Technol 11

26] C.S.P. Sastry, S.G. Rao, J .S .V. M L Rao, P.Y. Naidu

27] J. Ermer, J. Pharm. Biomed. Anal 24 (2001) 755 